\title{
The Spatial Pattern of Midsummer Drought as a Possible Mechanistic Response to Lower-Tropospheric Easterlies over the Intra-Americas Seas
}

\author{
DAVID MAXIMILIANO ZERMEÑO-DÍAZ \\ Department of Geography SUAyED, School of Philosophy and Letters, National Autonomous \\ University of Mexico (UNAM), Mexico City, Mexico
}

(Manuscript received 15 August 2018, in final form 9 September 2019)

\begin{abstract}
Following the idea that large-scale wind perturbations cause repeatable rainfall patterns over small tropical islands, the spatial pattern of the midsummer drought (MSD) is investigated as a repeatable rainfall pattern over the Intra-Americas Seas (IAS). For that, statistical techniques, including linear regressions, canonical correlation analysis, and variance budgets, were applied to the Tropical Rainfall Measuring Mission and ERA-Interim datasets to assess 1) the MSD pattern repeatability and 2) its explained variance in different time scales. As shown by the results, the MSD pattern is not a unique feature of the boreal summer intraseasonal variability in the IAS: it is more robust during summer but it exists in all rainy seasons on daily, intraseasonal, and interannual time scales. On diurnal time scales, the MSD pattern explains a negligible part of the total variance during summer $(<2 \%)$, but on interannual scales it explains up to $20 \%$ and it captures the spatial features of "El Niño" rainfall anomalies. On all time scales, the MSD pattern is accompanied by repeatable wind and pressure patterns: anomalous lower-tropospheric $(925 \mathrm{hPa})$ easterlies over a domain-wide meridional northward pressure gradient. These results provide evidence for the hypothesis that the MSD pattern manifests an underlying geographically determined, mechanistic pattern. Also, they suggest that the repeatable MSD-shaped rainfall and wind patterns could be extrapolated in time to better understand the climatic conditions behind droughts and pluvials, and to diagnose the causes behind rainfall trends.
\end{abstract}

\section{Introduction}

The Intra-Americas Seas (IAS) domain hosts a vast number of different weather and climate phenomena. This region, which includes Central America and southern Mexico, the Caribbean Sea, the Greater and Lower Antilles, and the northeastern tropical Pacific (EPAC) (e.g., Fig. 1a), features pronounced coastline asymmetries, maritime lands with steep mountains, and warm sea surface temperatures (SST). The climate of the IAS includes tropical cyclones, numerous convective systems, a Caribbean low-level jet (CLLJ) and, notably, a diurnal cycle with one of the largest amplitudes in the world (Sorooshian et al. 2002; Yang and Slingo 2001; Mapes et al. 2003; Nesbitt and Zipser 2003; Xie et al. 2005; Amador et al. 2006; Kikuchi and Wang 2008; Wang and Lee 2007; Serra et al. 2010; Biasutti et al. 2012). In addition, the IAS hosts phenomena formed elsewhere, such as African easterly waves, the Madden-Julian

Corresponding author: David Maximiliano Zermeño-Díaz, zermeno@comunidad.unam.mx oscillation (MJO), El Niño-Southern Oscillation (ENSO), and various other ocean-atmosphere modes (e.g., Enfield and Alfaro 1999; Wang 2007; Martin and Schumacher 2011a; Whitaker and Maloney 2018).

Despite such remarkable variability, it could be argued that the climatic richness of the IAS is constrained by geographical factors (e.g., Sobel et al. 2011). More specifically, its pronounced orographic effects might act to constrain the patterns in which the regional variability is manifested across time. This study proposes that a pattern of such geographically constrained nature is that characterizing the most notable climatological feature of the intraseasonal variability in the region, that of the midsummer drought (MSD).

The MSD is a relative minimum in rainfall during July and August, with respect to the June-to-September mean (e.g., Fig. 1c), that occurs over the EPAC (Magaña et al. 1999) and over the Caribbean (Martin and Schumacher 2011b). In general, the spatial pattern of the MSD (e.g., Fig. 2a) has been shown to be caused by the interactions between orographic effects and an anomalously intensified low-level flow (Small et al. 2007; Karnauskas et al. 2013; 

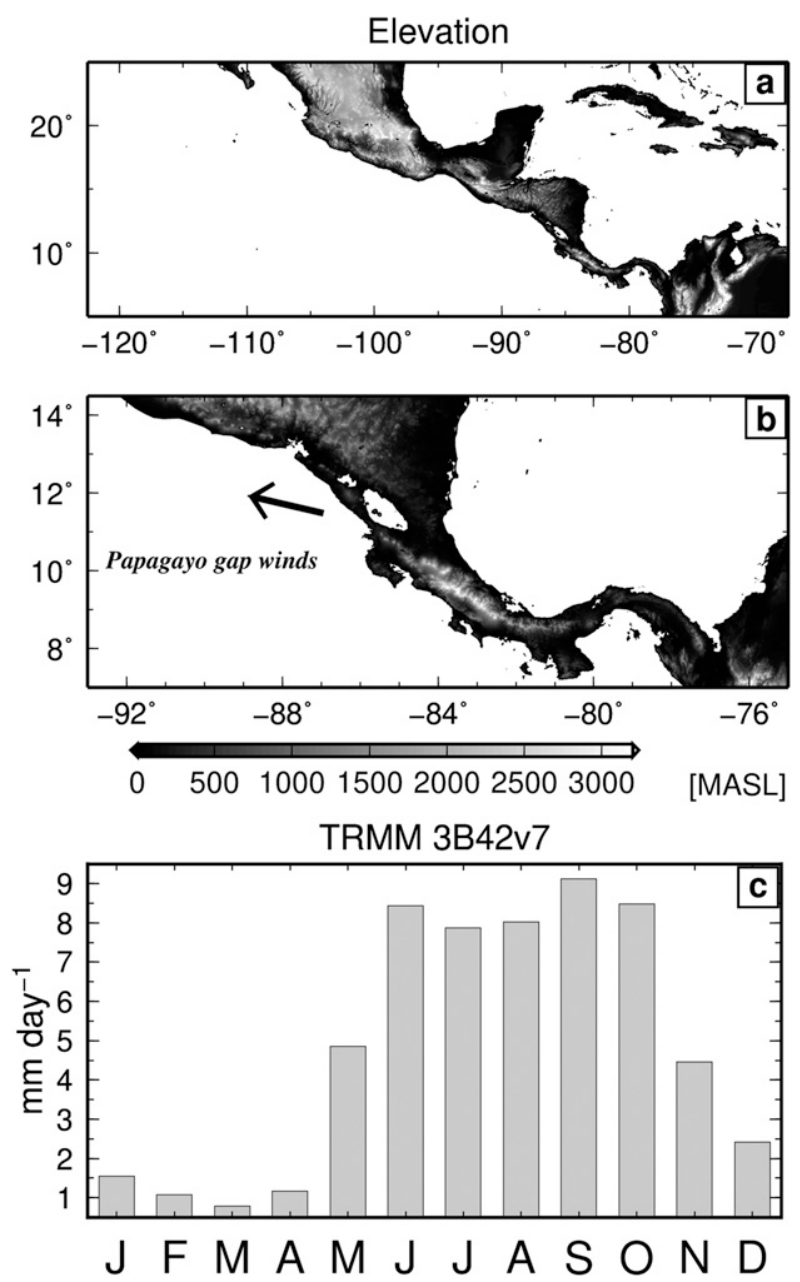

FIG. 1. Elevation (a) in the Intra-Americas Seas domain (IAS; $5^{\circ}-25^{\circ} \mathrm{N}, 60^{\circ}-115^{\circ} \mathrm{W}$ ), with (b) a magnification of the Papagayo gap region, and (c) the monthly distribution of TRMM-3B42 precipitation $\left(0.25^{\circ} \times 0.25^{\circ}\right.$ spatial resolution $)$ over the IAS domain. The black arrow schematizes Papagayo gap winds.

Mapes et al. 2005; Kelly and Mapes 2013). In particular, the causes behind the characteristic dry and wet features of the MSD pattern can be simplistically viewed as follows. The CLLJ, intensified by an intruding North Atlantic subtropical high (NASH; Kelly and Mapes 2011), causes wet anomalies over the eastern side of the Caribbean but dry anomalies over its western side during July and August (Wang 2007; Cook and Vizy 2010). The intensified CLLJ (instead of deflecting northward toward the southern United States as it does during June and September) crosses Central America, causing dry anomalies over the Gulf of Mexico and its surrounding regions (Mestas-Nuñez et al. 2007; Martin and Schumacher 2011b). Upon encountering the topographic effects from Central America, the CLLJ 1) causes intense wet anomalies over its exit region, over the eastern coasts of Costa Rica and Nicaragua, and 2) it also intensifies the Papagayo gap winds (e.g., Fig. 1b). Intense Papagayo gap winds displace the EPAC intertropical convergence zone (ITCZ) offshore, causing wet anomalies that extend from the Colombia-Panama Bight northwestward. Also, intense Papagayo gap winds, along with the offshore displacement of the ITCZ, cause the well-known dry anomalies over southern Mexico and western Central America, and over their Pacific coasts (Magaña and Caetano 2005).

In light of recent work that explored the effects of different wind regimes on the rainfall over small tropical islands (e.g., Kirshbaum 2011; Sobel et al. 2011), the relation between wind regimes and rainfall anomalies in the IAS may be considered from a more general perspective. As shown by Wang and Sobel (2017), rainfall over tropical islands (and their close vicinity) is enhanced under weak wind regimes but reduced under intense regimes. The reduction in rainfall is larger over the regions where the diurnal cycle is more pronounced. Parallels can be drawn between these results and those related to the MSD. First, convection during the MSD is suppressed under intense easterlies. Second, the MSD is more pronounced over regions where the diurnal convection is also more pronounced, over the southwestern Mexican coast (Magaña et al. 1999; Small et al. 2007; Kikuchi and Wang 2008). Of course these parallels are not simple: wind variations would produce a spatially more complex response over the IAS than that over a small island. Still, if that more complex response is a result of coherent, repeatable processes, then it might be more easily discovered in the more evident and more repeatable instance: in the climatological MSD.

To test whether such unified pattern may exist, we analyzed the relation between the rainfall variability and the MSD pattern under different wind regimes using observational and reanalysis data with different temporal and spatial resolutions. The next sections of this article are organized as follows. Section 2 describes the used data and methods. Section 3 explains the general strategy and provide technical information about the applied methods. Sections 4 and 5 both explain the applied methods and present their results. Section 6, after a brief summary, provides conclusions.

\section{Data}

The main datasets used are the European Centre for Medium-Range Weather Forecasts interim reanalysis (ERA-Interim; $0.5^{\circ} \times 0.5^{\circ}$; 6-hourly; Dee et al. 2011) and the Tropical Rainfall Measuring Mission (TRMM) rainfall estimates version $3 \mathrm{~B} 42 \mathrm{v} 7\left(0.25^{\circ} \times 0.25^{\circ}\right.$; 3-hourly; Huffman et al. 2007). Other complementary datasets are 1) the Precipitation Estimation from Remotely Sensed Information using Artificial Neural Networks for Climate 

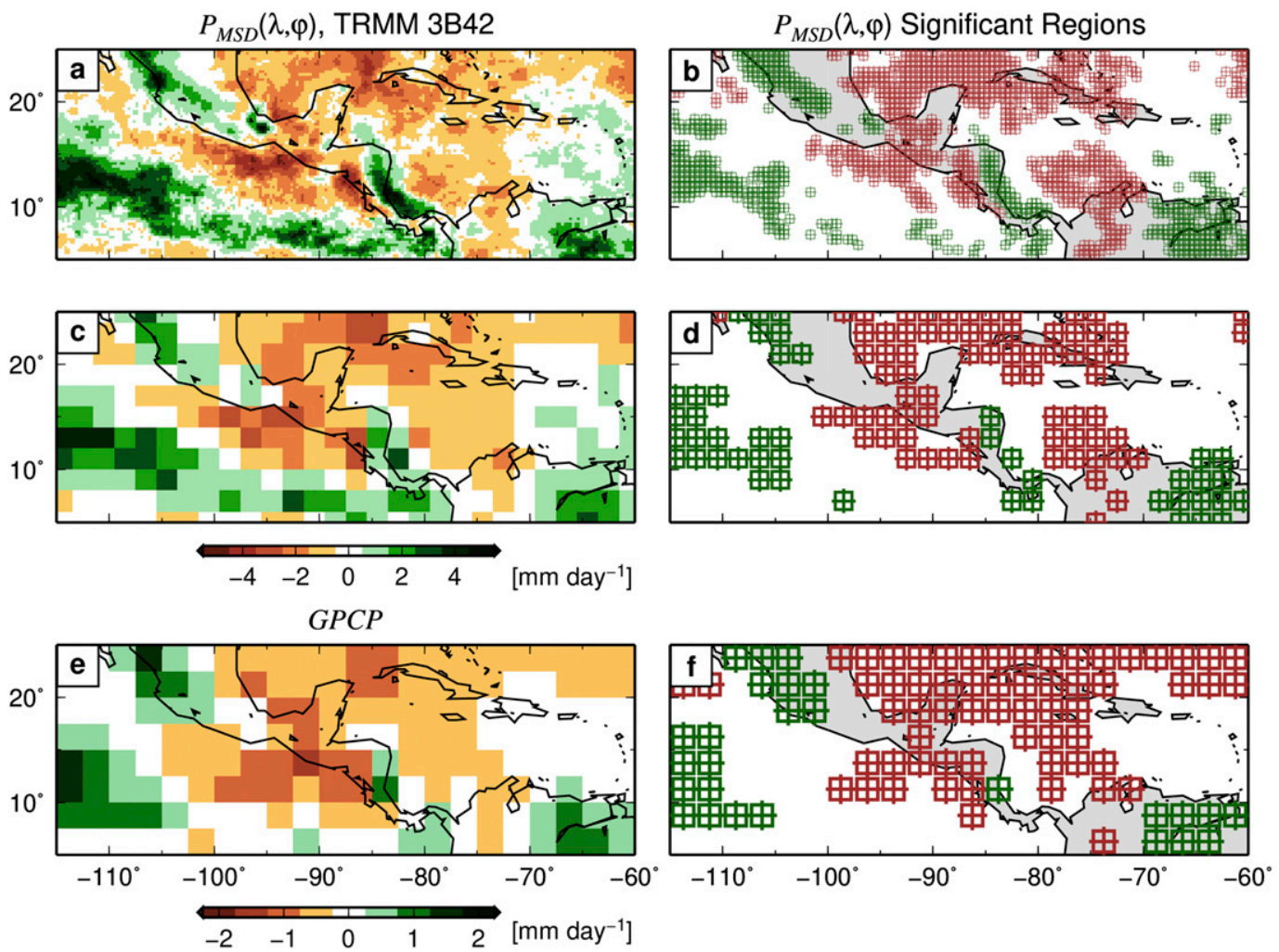

FIG. 2. The spatial pattern of the climatological midsummer drought in anomalous precipitation, $P_{\mathrm{MSD}}(\lambda, \varphi)$, calculated as the difference between the monthly mean of July-August (JA) and that of June-September (JJAS), using TRMM 3B42 (a) at $0.25^{\circ} \times 0.25^{\circ}$ and (c) at $2^{\circ} \times 2^{\circ}$ spatial resolutions, and using (e) GPCP at $2.5^{\circ} \times 2.5^{\circ}$. (b),(d),(f) The statistically significant regions at $95 \%$ confidence level are shown with squares that are highlighted by the sign of the anomalies (brown are negative, red are positive).

Data Record (PERSIANN; $0.25^{\circ} \times 0.25^{\circ}$; daily; Ashouri et al. 2015), 2) the Global Precipitation Climatology Project (GPCP) version 2.3 Combined Precipitation Dataset $\left(2.5^{\circ} \times\right.$ 2.5 ; monthly; Adler et al. 2003), 3) the Climate Forecast System Reanalysis (CFSR; $0.5^{\circ} \times 0.5^{\circ}$; 6 -hourly; Saha et al. 2010), and 4) the time series of SST anomalies over the Niño-3.4 domain $\left(\mathrm{SST}_{3.4}\right)$ from the Extended Reconstructed Sea Surface Temperature (ERSST) version 5 dataset (Huang et al. 2017; available online at www.cpc.ncep.noaa. gov/data/indices/ersst5.nino.mth.81-10.ascii).

Analyses at daily and monthly temporal resolutions were restricted to the 15-yr period during which the TRMM satellite gathered complete years of data, 1998-2012. Analyses at seasonal temporal resolutions used the period of the available GPCP and ERA-Interim data, 1979-2017. In space, all analyses were restricted to the IAS domain considered in this study: $5^{\circ}-25^{\circ} \mathrm{N}, 60^{\circ}-115^{\circ} \mathrm{W}$ (e.g., Fig. 1a).

\section{Methodology}

As general strategy we investigated the MSD pattern in the temporal domain and resolution where it is known to exist (first), and in other temporal domains and resolutions where it is not known to exist (second). First, we isolated the MSD pattern from the monthly climatology of June-September (JJAS) rainfall (the known temporal domain of the MSD pattern). Second, we sought MSDlike patterns in daily, monthly, and interannual rainfall anomalies in JJAS and in other periods (unknown temporal domains of the MSD pattern). In the first part of this approach, the climatological MSD pattern was isolated by means of the calendar, but in the second part, MSDlike patterns in anomalous rainfall were sought by means of their likely trigger: lower-tropospheric winds.

Our approach was statistical. We calculated means and anomalies of all variables on several temporal scales (section 3a). We estimated space-time variances to estimate the importance of the detected MSD patterns. We used point regressions to extract spatial signals related to the MSD pattern, and spatial correlations (i.e., pixel-by-pixel correlation between two two-dimensional fields) to compare the resemblance between two given fields. Also, we used canonical correlation analysis (CCA) - a technique used for isolating spatial patterns in two fields that tend to 
occur synchronously with each other (Wallace et al. 1992) to investigate wind and pressure patterns that tend to occur synchronously with MSD-like rainfall patterns.

Specific details about the application of these techniques in our approach are provided along with their results in sections 4 and 5; other technical details are the following. Correlations in all cases are Pearson's correlations. Statistical significance was tested at the $95 \%$ level using the Student's $t$ test. CCA was computed with the Climate Predictability Tool (CPT; available online at http://iri.columbia.edu/our-expertise/climate/tools/cpt/). Rainfall data were spatially regridded using a first-order conservative interpolation scheme, remapcon from the Climate Data Operators (CDO; available online at https://code.mpimet.mpg.de/projects/cdo/).

\section{Treatment of the time dimension}

To explicitly show the temporal resolution of the several analyzed variables in the two following sections, any field, $X$, that depends on longitude $(\lambda)$, latitude $(\varphi)$, and time $(t)$ was treated as a field that does not directly depend on time; it was treated as a field that depends on calendar variables, years (yy), months (mm), and days (dd): $X(\lambda, \varphi, t) \equiv X$ $(\lambda, \varphi, \mathrm{yy}, \mathrm{mm}, \mathrm{dd})$. With this symbolic treatment, daily [Eq. (1)], monthly [Eq. (2)], and interannual [Eq. (3)] anomalies of $X$ are calculated with the following expressions:

$$
\begin{aligned}
X^{\prime}(\lambda, \varphi, \mathrm{yy}, \mathrm{mm}, \mathrm{dd})= & X(\lambda, \varphi, \mathrm{yy}, \mathrm{mm}, \mathrm{dd}) \\
& -X(\lambda, \varphi,[\mathrm{yy}], \mathrm{mm}, \mathrm{dd}), \\
X^{\prime}(\lambda, \varphi, \mathrm{yy}, \mathrm{mm})= & X(\lambda, \varphi, \mathrm{yy}, \mathrm{mm},[\mathrm{dd}]) \\
& -X(\lambda, \varphi,[\mathrm{yy}], \mathrm{mm},[\mathrm{dd}]), \\
X^{\prime}(\lambda, \varphi, \mathrm{yy})_{\mathrm{mm}}= & X(\lambda, \varphi, \mathrm{yy},[\mathrm{mm}],[\mathrm{dd}]) \\
& -X(\lambda, \varphi,[\mathrm{yy}],[\mathrm{mm}],[\mathrm{dd}]),
\end{aligned}
$$

where primes indicate anomalies and squared brackets the arithmetic mean operator, and $X(\lambda, \varphi,[\mathrm{yy}], \mathrm{mm}, \mathrm{dd})$ are daily means, $X(\lambda, \varphi,[\mathrm{yy}], \mathrm{mm},[\mathrm{dd}])$ monthly means, and $X(\lambda, \varphi,[\mathrm{yy}],[\mathrm{mm}],[\mathrm{dd}])$ annual means.

\section{The spatial pattern of the MSD}

The spatial pattern of the MSD was estimated as the precipitation $(P)$ differences between the mean of July and August (JA) and that of JJAS:

$$
\begin{aligned}
P_{\mathrm{MSD}}(\lambda, \varphi)= & P(\lambda, \varphi,[\mathrm{yy}],[\mathrm{JA}],[\mathrm{dd}]) \\
& -P(\lambda, \varphi,[\mathrm{yy}],[\mathrm{JJAS}],[\mathrm{dd}]),
\end{aligned}
$$

where $P_{\mathrm{MSD}}(\lambda, \varphi)$ is the spatial pattern of the MSD-the pattern to be sought on different time scales. Consistently with previous studies (e.g., Fig. 6c in Magaña et al. 1999), $P_{\mathrm{MSD}}(\lambda, \varphi)$ (Figs. 2a,b) captures the characteristic negative and positive rainfall anomalies of the climatological MSD pattern. ${ }^{1}$ The negative anomalies are located over the Caribbean Sea (including the Greater Antilles and western Venezuela and parts of Colombia), the Gulf of Mexico, and the coastal regions of western Central America and southern Mexico. The positive anomalies are located over the eastern Caribbean (including the Lower Antilles and eastern Venezuela), the Caribbean coasts of Costa Rica and Nicaragua, and over an elongated region that extends from the Colombia-Panama Bight northwestward. The positive rainfall anomalies located over northeastern Mexico are not part of the MSD signal; they are part of the onset of the North American monsoon (e.g., Johnson et al. 2007).

The sensitivity of $P_{\mathrm{MSD}}(\lambda, \varphi)$ was tested by modifying Eq. (4): JA and JJAS rainfall differences were replaced with those between August and July. Such modification resulted in less statistically significant anomalies covering the Caribbean and southern Mexico. From this result, and in accordance with previous studies (e.g., Small et al. 2007), Eq. (4) was considered adequate to estimate $P_{\mathrm{MSD}}(\lambda, \varphi)$.

We focused on the broad features of the MSD pattern. To identify such features, we regridded TRMM 3B42 from its original $0.25^{\circ} \times 0.25^{\circ}$ resolution (Figs. 2a,b) into $1^{\circ} \times 1^{\circ}$ (not shown) and $2^{\circ} \times 2^{\circ}$ (Figs. 2c,d) resolutions; then, we compared $P_{\mathrm{MSD}}(\lambda, \varphi)$ in these datasets and with that in GPCP $\left(2.5^{\circ} \times 2.5^{\circ}\right.$; Figs. 2 e,f). $P_{\mathrm{MSD}}(\lambda, \varphi)$ in all datasets has similar features (Fig. 2), except that in the coarse-resolution datasets $\left(\mathrm{TRMM}\right.$ at $2^{\circ} \times 2^{\circ}$ and GPCP), $P_{\mathrm{MSD}}(\lambda, \varphi)$ has weak signals over the equatorial EPAC, and over the Caribbean coasts of Nicaragua, Costa Rica, and Panama. Since these signals are particularly weak in GPCP, GPCP was used only for analyses at interannual scales; TRMM at $2^{\circ} \times 2^{\circ}$ was used for analyses at daily and monthly scales.

\section{Variance budget}

The variability contribution of different MSD-like rainfall structures was estimated by calculating spacetime variances and by comparing them using a budget analysis. This subsection focuses on estimating the JJAS rainfall variability contributions of 1) the monthly climatological MSD and 2) those of monthly anomalous variability with MSD-like features.

\footnotetext{
${ }^{1}$ A summary of the causes commonly attributed to the spatial features of the MSD pattern is provided in the third paragraph of section 1.
} 
To estimate the variance attributable to the climatological MSD we formed a dataset that has $P_{\mathrm{MSD}}$ $(\lambda, \varphi)$ in July and August, and its opposite signals in June and September. Such a dataset, $P_{\text {MSD_JJAs }_{-}}(\lambda, \varphi$, JJAS), can be interpreted as the monthly evolution in JJAS of the climatological MSD. The variance of this dataset is related to that of the total monthly means by:

$$
\begin{aligned}
& \operatorname{var}_{\text {space-time }}\{P(\lambda, \varphi,[\mathrm{yr}], \mathrm{JJAS},[\mathrm{dd}])\} \\
& \quad=\operatorname{var}_{\text {space-time }}\left[P_{\text {MSD_JJAS }}(\lambda, \varphi, \text { JJAS })\right]+R_{\text {CLIM_JJAS }},
\end{aligned}
$$

where var $_{\text {space-time }}$ indicates that space-time variance was calculated to a given dataset; $R_{\text {CLIM JJAS }}$ is the variance from monthly-mean variability that is not related to the climatological MSD (residual variance).

To estimate the variance attributable to the anomalous variability with MSD-like features, we linearly reconstructed $P^{\prime}(\lambda, \varphi, \mathrm{yr}, \mathrm{JJAS})$ based on $P_{\mathrm{MSD}}(\lambda, \varphi)$ to form a dataset of the projections of anomalous monthly variability on the MSD pattern. Such a dataset, $P_{\text {MSD PROJ }}^{\prime}(\lambda, \varphi, \mathrm{yr}, \mathrm{JJ} A S)$, can be interpreted as an approximation to the anomalous variability with MSD-like features. The variance of this dataset is related to that of the total monthly anomalies by

$$
\begin{aligned}
& \operatorname{var}_{\text {space-time }}\left[P^{\prime}(\lambda, \varphi, \mathrm{yr}, \mathrm{JJAS})\right] \\
& =\operatorname{var}_{\text {space-time }}\left[P_{\text {MSD_PROJ }}^{\prime}(\lambda, \varphi, \mathrm{yr}, \mathrm{JJAS})\right] \\
& \quad+R_{\text {ANOM_JJAS }},
\end{aligned}
$$

where $R_{\text {ANOM_JJAS }}$ is the variance explained by monthly, anomalous variability without $P_{\mathrm{MSD}}(\lambda, \varphi)$ features (residual variance). By means of Eq. (2), the right-hand side terms of Eqs. (5) and (6) are related to the total monthly variance of $P$ by:

$$
\begin{aligned}
\operatorname{var}_{\text {space-time }}\{P(\lambda, \varphi, \mathrm{yr}, \mathrm{JJAS},[\mathrm{dd}])\} \\
=\operatorname{var}_{\text {space-time }}\left[P_{\text {MSD_JJAS }}(\lambda, \varphi, \mathrm{JJAS})\right] \\
\quad+\operatorname{var}_{\text {space-time }}\left[P_{\text {MSD_PROJ }}^{\prime}(\lambda, \varphi, \mathrm{yr}, \mathrm{JJAS})\right] \\
\quad+\left(R_{\text {CLIM_JJAS }}+R_{\text {ANOM_JJAS }}\right) .
\end{aligned}
$$

The amount of variance explained by 1$)$ the climatological MSD, $\operatorname{var}_{\text {space-time }}\left[P_{\text {MSD_JJAS }}(\lambda, \varphi\right.$, JJAS $\left.)\right]$ with respect to the total JJAS variance, $\operatorname{var}_{\text {space-time }}\{P(\lambda, \varphi, \mathrm{yr}$, JJAS, [dd]\} (Table 1, row 1), is 10.4\% (Table 1, row 5);

\begin{tabular}{|c|c|c|}
\hline No. & Precipitation field & $\operatorname{Var}_{\text {space-time }}$ \\
\hline 1 & $P(\lambda, \varphi, \mathrm{yr}, \mathrm{JJAS},[\mathrm{dd}])$ & $8.2 \mathrm{~mm}^{2} \mathrm{day}^{-2}(100 \%)$ \\
\hline 2 & $P^{\prime}(\lambda, \varphi, \mathrm{yr}, \mathrm{JJAS})$ & $6.4 \mathrm{~mm}^{2}$ day $^{-2}(77.1 \%)$ \\
\hline 3 & $P(\lambda, \varphi,[\mathrm{yr}], \mathrm{JJ} A S,[\mathrm{dd}])$ & $1.9 \mathrm{~mm}^{2}$ day $^{-2}(22.9 \%)$ \\
\hline 4 & $P_{\text {MSD PROJ }}^{\prime}(\lambda, \varphi, \mathrm{yr}, \mathrm{JJ} A S)$ & $0.9 \mathrm{~mm}^{2} \mathrm{day}^{-2}(10.4 \%)$ \\
\hline 5 & $P_{\text {MSD_JJAS }}(\lambda, \varphi$, JJAS $)$ & $0.4 \mathrm{~mm}^{2}$ day $^{-2}(5.3 \%)$ \\
\hline 6 & $P_{\mathrm{CCA} u^{\prime}}^{\prime}(\lambda, \varphi)$ & $0.27 \mathrm{~mm}^{2}$ day $^{-2}(2.1 \%)$ \\
\hline 7 & $P_{\mathrm{CCA} v^{\prime}}^{\prime}(\lambda, \varphi)$ & $0.17 \mathrm{~mm}^{2}$ day $^{-2}(2.1 \%)$ \\
\hline 8 & $P_{\mathrm{CCA} Z^{\prime}}^{\prime}(\lambda, \varphi)$ & $0.17 \mathrm{~mm}^{2} \mathrm{day}^{-2}(2.1 \%)$ \\
\hline 9 & $P(\lambda, \varphi, \mathrm{yr}, \mathrm{JJAS}, \mathrm{dd})$ & $123.5 \mathrm{~mm}^{2}$ day $^{-2}(100 \%)$ \\
\hline 10 & $P^{\prime}(\lambda, \varphi, \mathrm{yr}, \mathrm{JJAS}, \mathrm{dd})$ & $113.6 \mathrm{~mm}^{2}$ day $^{-2}(92 \%)$ \\
\hline 11 & $P_{\mathrm{REG}_{-} u}^{\prime}(\lambda, \varphi, \mathrm{JJ} \mathrm{AS}, \mathrm{dd})$ & $2.3 \mathrm{~mm}^{2}$ day $^{-2}(1.9 \%)$ \\
\hline 12 & $P(\lambda, \varphi, \mathrm{yr}, \mathrm{MON}, \mathrm{dd})$ & $111.6 \mathrm{~mm}^{2}$ day $^{-2}(100 \%)$ \\
\hline 13 & $P^{\prime}(\lambda, \varphi, \mathrm{yr}, \mathrm{MON}, \mathrm{dd})$ & $99.3 \mathrm{~mm}^{2}$ day $^{-2}(89 \%)$ \\
\hline 14 & $P_{\mathrm{REG}_{u}}^{\prime}(\lambda, \varphi, \mathrm{MON}, \mathrm{dd})$ & $1.5 \mathrm{~mm}^{2} \mathrm{day}^{-2}(1.3 \%)$ \\
\hline 15 & $\operatorname{GPCP}^{\prime}(\lambda, \varphi, \mathrm{yr},[\mathrm{JJAS}])$ & $1.5 \mathrm{~mm}^{2} \mathrm{day}^{-2}(100 \%)$ \\
\hline 16 & $\mathrm{GPCP}_{\mathrm{REG} u}^{\prime}(\lambda, \varphi, \mathrm{yr},[\mathrm{JJAS}])$ & $0.3 \mathrm{~mm}^{2} \mathrm{day}^{-2}(20.2 \%)$ \\
\hline 17 & $\operatorname{GPCP}^{\prime}(\lambda, \varphi, \mathrm{yr},[\mathrm{MON}])$ & $1.52 \mathrm{~mm}^{2}$ day $^{-2}(100 \%)$ \\
\hline 18 & $\operatorname{GPCP}_{\mathrm{REG} \_u}^{\prime}(\lambda, \varphi, \mathrm{yr},[\mathrm{MON}])$ & $0.16 \mathrm{~mm}^{2}$ day $^{-2}(10.2 \%)$ \\
\hline
\end{tabular}
the amount of variance explained by 2) anomalous variability with MSD-like features, var $_{\text {space-time }}$ $\left[P_{\text {MSD_PROJ }}^{\prime}(\lambda, \varphi\right.$, yr, JJAS)], is $5.3 \%$ (Table 1 , row 4). By adding both amounts, the variance explained by
TABLE 1. Space-time variances of precipitation fields from different temporal resolution domains all at $2^{\circ} \times 2^{\circ}$ spatial resolutions. Variance values $\left(\mathrm{mm}^{2} \mathrm{day}^{-2}\right)$ and fractions $(\%)$ of the total variance (of its temporal resolution domain) are shown.

variability with $P_{\mathrm{MSD}}(\lambda, \varphi)$ features is $15.7 \% .^{2}$ These estimations indicate that the variance that cannot be attributed to MSD patterns, the sum of $R_{\text {CLIM_JJAS }}$ and $R_{\text {ANOM_JJAS }}$, is close to $84.3 \%$. However, all these estimations depend on the size of the chosen domain: they include all regions within the selected IAS domain (e.g., Fig. 1a). By including only statistically significant regions in $P_{\mathrm{MSD}}(\lambda, \varphi)$ (which at $2^{\circ} \times 2^{\circ}$ covers $38 \%$ of the IAS domain; Fig. 2c), the fractional variance attributable to variability with $P_{\mathrm{MSD}}(\lambda, \varphi)$ features, climatological and anomalous, is $30 \%$.

\section{Multiscale repeatability of MSD-wind patterns}

We sought MSD-like patterns in the anomalous rainfall variability in different time scales; while different techniques could be used for that, we used CCA, composites, and regressions. Since MSD-like anomalous patterns are likely connected to lower-tropospheric wind and geopotential height $(Z)$, we applied these statistical techniques having rainfall as the dependent variable and wind and $Z$ as independent variables. We started these analyses by identifying the wind and $Z$ fields during the climatological MSD (section 5a); after that, we sought anomalous MSD-like rainfall patterns (with their associated wind and $Z$ patterns) in daily (section $5 \mathrm{~b}$ ),

\footnotetext{
${ }^{2}$ As the spatial resolution increase, the variance explained by variability with $P_{\mathrm{MSD}}(\lambda, \varphi)$ features decreases: at $1^{\circ} \times 1^{\circ}$ is $14.8 \%$, and at $0.25^{\circ} \times 0.25^{\circ}$ is $12.6 \%$.
} 

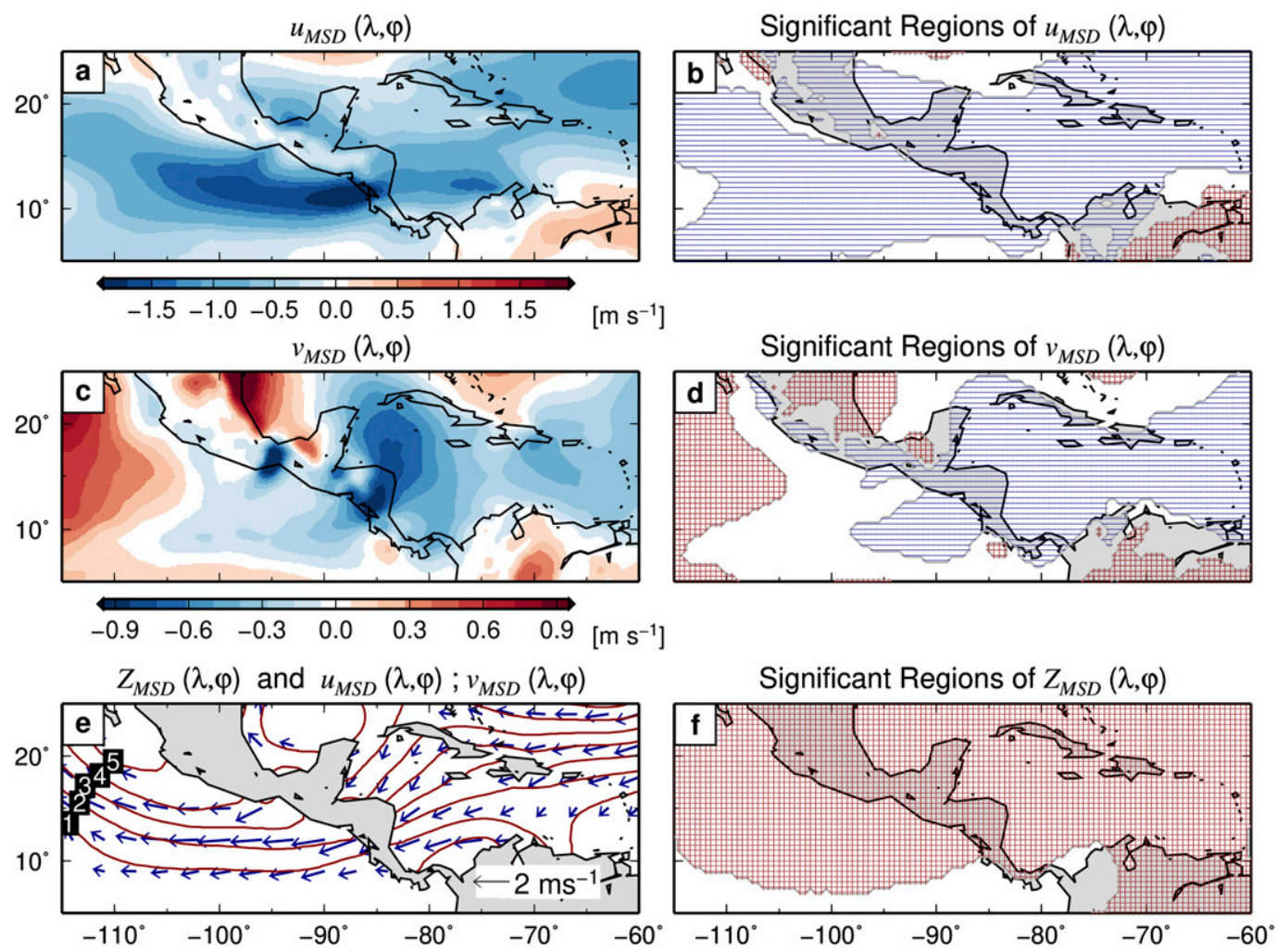

FIG. 3. As in Fig. 2, but for (a),(b) zonal (u) wind intensity, (c),(d) meridional ( $v$ ) wind intensity, and (e),(f) geopotential height $\left(Z ; \mathrm{m}\right.$; contours) at the 925 -hPa vertical pressure level from ERA Interim at $0.5^{\circ} \times 0.5^{\circ}$ spatial resolution. The $u-v$ wind field is also shown in (e) (arrows).

monthly (section 5c), and interannual (section 5d) scales in all seasons.

For consistency with previous studies (e.g., Amador et al. 2006; Martin and Schumacher 2011b; Herrera et al. 2015), the lower troposphere was represented by $925-$ $\mathrm{hPa}$ fields. Repetition of the analyses of this section with data at other vertical levels (from the surface to $850 \mathrm{hPa}$ ) yields qualitatively the same results.

\section{a. Monthly climatological wind-MSD patterns}

We applied Eq. (4) to monthly $925-\mathrm{hPa}$ horizontal $(u)$ and meridional $(v)$ winds and $Z$ to estimate the lower-tropospheric patterns associated with $P_{\mathrm{MSD}}(\lambda, \varphi)$. The pattern in $Z$ associated with $P_{\mathrm{MSD}}(\lambda, \varphi), Z_{\mathrm{MSD}}(\lambda, \varphi)$, is characterized by northward gradient that spans over most parts of the IAS domain (Figs. 3e,f). The patterns in $u$ and $v$ associated with $P_{\mathrm{MSD}}(\lambda, \varphi), u_{\mathrm{MSD}}(\lambda, \varphi)$, and $v_{\mathrm{MSD}}(\lambda, \varphi)$ (Figs. 3a-d) are characterized by enhanced easterlies impinging over Central America, and enhanced Papagayo and Tehuantepec gap winds over the EPAC. Although the main features of the anomalous patterns in Fig. 3 have been described by previous studies (e.g., Wang 2007; Cook and Vizy 2010), these patterns suggest no clear indication of whether influences from the Pacific or the Atlantic might cause them. They rather suggest that winds impinging over Central America could be pushed from the Atlantic, could be pulled from the Pacific, or both.

\section{b. Monthly anomalous wind-MSD patterns}

CCA, used to find pairs of optimally correlated patterns (e.g., Navarra and Simoncini 2010), was applied to find MSD patterns in the anomalous monthly variability of JJAS along with their optimally correlated $u$, $v$, and $Z$ patterns. In particular, CCA was applied to these pairs of fields: $u^{\prime}(\lambda, \varphi$, yy, JJAS $)$ and $P^{\prime}(\lambda, \varphi$, yy, JJAS); $v^{\prime}(\lambda, \varphi$, yy, JJAS $)$ and $P^{\prime}(\lambda, \varphi$, yy, JJAS $)$; and $Z^{\prime}(\lambda, \varphi$, yy, JJAS $)$ and $P^{\prime}(\lambda, \varphi$, yy, JJAS $)$. The spatial patterns of the leading CCA mode of these analyzes are shown in Fig. 4; they are identified using the following notation:

$X_{\mathrm{CCA}_{-} Y^{\prime}}^{\prime}(\lambda, \varphi)=\mathrm{CCA}\left[X^{\prime}(\lambda, \varphi, \mathrm{yy}, \mathrm{mm}), Y^{\prime}(\lambda, \varphi, \mathrm{yy}, \mathrm{mm})\right]$,

where $X_{\mathrm{CCA}_{-} Y^{\prime}}^{\prime}(\lambda, \varphi)$ are the $X$ spatial loadings from the CCA applied to two given fields of monthly anomalies, $X^{\prime}$ and $Y^{\prime}$. 

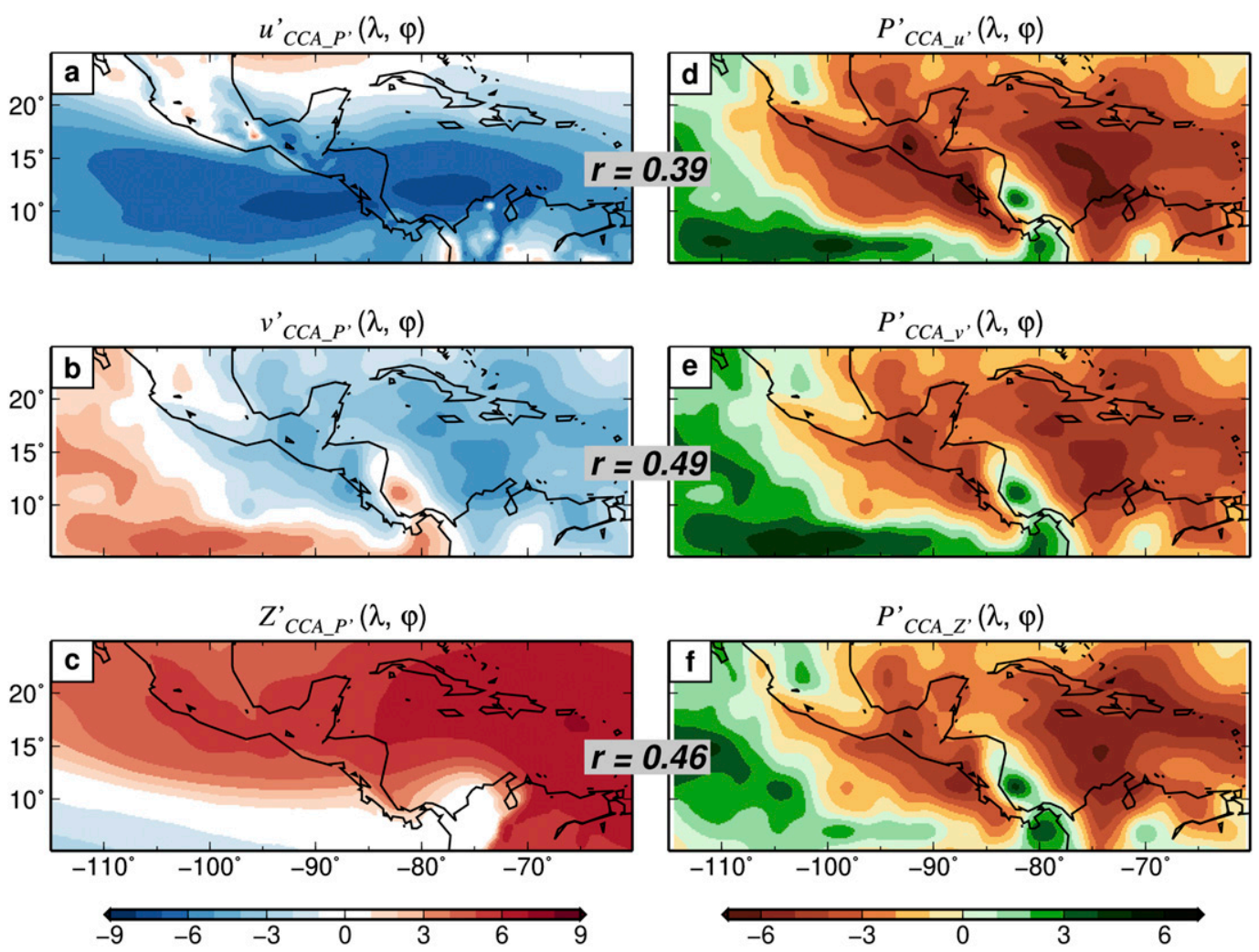

FIG. 4. CCA spatial loadings of the leading modes between JJAS monthly anomalies in (a),(b) zonal wind $(u)$ and TRMM 3B42 $\left(P ; 2^{\circ} \times 2^{\circ}\right.$ spatial resolution); (c),(d) meridional wind $(v)$ and $P$; and (e),(f) 925-hPa geopotential height $(Z)$ and $P$. Data of $u, v$, and $Z$ are at the 925 -hPa vertical pressure level from ERA-Interim. The canonical correlation coefficients $r$ are also shown.

The spatial features of $P_{\mathrm{MSD}}(\lambda, \varphi)$ are prominently present in all $P$ spatial loadings (Figs. 4d-f; Table 2, rows 1-3). Also, since the MSD pattern is present in all $P$ spatial loadings, $P_{\mathrm{MSD}}(\lambda, \varphi)$ can be interpreted as optimally correlated to the $u, v$, and $Z$ spatial loadings of Figs. $4 \mathrm{a}-\mathrm{c}$. The spatial loadings of $u, v$, and $Z$ feature intense easterlies impinging over Central America, intense Papagayo gap winds over the EPAC, and a northward $Z$ gradient covering most of the IAS domain. Although the fraction of the total space-time variance of monthly $P$ explained by either of the CCA modes in the three analyzed cases (Figs. $4 \mathrm{~d}-\mathrm{f}$ ) is almost negligible (around 2\%; Table 1, rows 6-8), these results show that patterns with MSD-like features are indeed detectable in the anomalous variability of monthly rainfall. Also, these results show that anomalous MSD-like patterns are associated with domain-wide anomalies in wind and pressure that resemble those during the climatological MSD.

\section{c. Anomalous daily wind-MSD patterns}

The existence of MSD-like patterns in daily and also in interannual temporal scales was investigated using a simple index. Such an index is the time series at a representative point in the region of the Papagayo gap winds, at $10^{\circ} \mathrm{N}, 90^{\circ} \mathrm{W}: u_{10 \mathrm{~N}, 90 \mathrm{~W}}(\mathrm{yy}, \mathrm{mm}, \mathrm{dd})$. This index was found by seeking daily resolution signals in $u$ and $Z$ during JJAS that would better capture $u_{\mathrm{MSD}}(\lambda, \varphi)$ and $Z_{\mathrm{MSD}}(\lambda, \varphi)$ (i.e., the $u$ and $Z$ signals associated with the climatological MSD; Figs. 3a and 3e). Those signals were sought in one-point regression maps of daily $u$ and $Z$. The regression maps of daily $u$ and $Z$ that captured maximal $u_{\mathrm{MSD}}(\lambda, \varphi)$ and $Z_{\mathrm{MSD}}(\lambda, \varphi)$ signals were those onto $u$ at the Papagayo gap region (Figs. 5a,b). More specifically, $u_{\mathrm{MSD}}(\lambda, \varphi)$ and $Z_{\mathrm{MSD}}(\lambda, \varphi)$ have the largest spatial correlations with regressed maps of $u(\lambda, \varphi$, yy, JJAS, dd) and $Z\left(\lambda, \varphi\right.$, yy, JJAS, dd) onto $u_{10 \mathrm{~N}, 90 \mathrm{w}}$ (yy, JJAS, dd) (Table 2, rows 4 and 5).

A test of the validity of the constructed index, $u_{10 \mathrm{~N}, 90 \mathrm{~W}}$ (yy, JJAS, dd), is presented here by comparing $u_{\mathrm{MSD}}(\lambda, \varphi)$ and $Z_{\mathrm{MSD}}(\lambda, \varphi)$ [the $u$ and $Z$ fields associated with $\left.P_{\mathrm{MSD}}(\lambda, \varphi)\right]$ with the regressed $u$ and $Z$ fields onto 1 ) $u_{10 \mathrm{~N}, 90 \mathrm{w}}$ (yy, JJAS, dd), and onto 2) a known $u$ index of CLLJ intensity (Cook and Vizy 2010). The latter (here referred to as $u_{\text {CLLJ }}$ ) is the time series of $u$ averaged over $128^{\circ}-158^{\circ} \mathrm{N}, 70^{\circ}-75^{\circ} \mathrm{W}$. The spatial correlations between the regressed $u$ and $Z$ fields onto $u_{10 \mathrm{~N}, 90 \mathrm{~W}}$ 
TABLE 2. Person's coefficients of spatial correlations $\left(r_{\text {spatial }}\right)$ between pairs of two-dimensional fields. All coefficients are statistically significant at the $95 \%$ confidence level.

\begin{tabular}{|c|c|c|c|}
\hline No. & Field 1 & Field 2 & $r_{\text {spatial }}$ \\
\hline 1 & $P_{\mathrm{CCA} u^{\prime}}^{\prime}(\lambda, \varphi)($ Fig. $4 \mathrm{~d})$ & $P_{\mathrm{MSD}}(\lambda, \varphi)($ Fig. $2 \mathrm{c})$ & 0.72 \\
\hline 2 & $P_{\mathrm{CCA}_{-} v^{\prime}}^{\prime}(\lambda, \varphi)($ Fig. $4 \mathrm{e})$ & $P_{\mathrm{MSD}}(\lambda, \varphi)($ Fig. $2 \mathrm{c})$ & 0.77 \\
\hline 3 & $P_{\text {CCA_ } Z^{\prime}}^{\prime}(\lambda, \varphi)$ (Fig. 4f) & $P_{\mathrm{MSD}}(\lambda, \varphi)($ Fig. $2 \mathrm{c})$ & 0.77 \\
\hline 4 & $u_{\text {REG_u }}^{\prime}(\lambda, \varphi)$ (Fig. 5a) & $u_{\mathrm{MSD}}(\lambda, \varphi)$ (Fig. 2c) & -0.78 \\
\hline 5 & $Z_{\mathrm{REG} \_u}^{\prime}(\lambda, \varphi)($ Fig. $5 \mathrm{~b})$ & $Z_{\mathrm{MSD}}(\lambda, \varphi)($ Fig. $2 \mathrm{c})$ & -0.55 \\
\hline 6 & $u_{\text {REG_CLLJ }}^{\prime}(\lambda, \varphi)($ Fig. $5 \mathrm{c})$ & $u_{\mathrm{MSD}}(\lambda, \varphi)$ (Fig. 2c) & -0.6 \\
\hline 7 & $Z_{\text {REG CLLJ }}^{\prime}(\lambda, \varphi)$ (Fig. $\left.5 \mathrm{~d}\right)$ & $Z_{\mathrm{MSD}}(\lambda, \varphi)$ (Fig. 2c) & -0.35 \\
\hline 8 & $P^{\prime}(\lambda, \varphi,[$ yy], [JJAS], [“easterlies”] $)($ Fig. 8a) & $P_{\mathrm{MSD}}(\lambda, \varphi)$ (Fig. 2c) & 0.72 \\
\hline 9 & $Z^{\prime}(\lambda, \varphi,[y y],[J J A S],[“ e a s t e r l i e s ”])($ Fig. 8b) & $Z_{\mathrm{MSD}}(\lambda, \varphi)$ (Fig. $\left.2 \mathrm{c}\right)$ & 0.93 \\
\hline 10 & $P_{\text {REG_ } u^{\prime}}^{\prime}(\lambda, \varphi)_{\text {JJAS }}$ (Fig. 9b) & $P_{\mathrm{MSD}}^{\prime}(\lambda, \varphi)($ Fig. $2 \mathrm{c})$ & -0.72 \\
\hline 11 & $P_{\mathrm{REG} \_u^{\prime}}^{\prime}(\lambda, \varphi)_{\mathrm{MON}}($ Fig. 9c) & $P_{\mathrm{MSD}}^{\prime}(\lambda, \varphi)$ (Fig. 2c) & -0.68 \\
\hline 12 & $P_{\text {REG_ } u^{\prime}}^{\prime}(\lambda, \varphi)_{\text {DJFMA }}$ (Fig. 9a) & $P_{\mathrm{MSD}}^{\prime}(\lambda, \varphi)($ Fig. $2 \mathrm{c})$ & -0.47 \\
\hline 13 & $\begin{array}{l}\operatorname{GPCP}^{\prime}(\lambda, \varphi,[\text { ["El Niño"], [JJAS]) } \\
\quad \text { (Fig. 10) }\end{array}$ & $P_{\mathrm{MSD}}^{\prime}(\lambda, \varphi)_{\mathrm{GPCP}}($ Fig. 2e) & 0.35 \\
\hline 14 & $\operatorname{GPCP}_{\text {REG_} \_u^{\prime}}^{\prime}(\lambda, \varphi)_{\text {JJAS }}($ Fig. 11a) & $P_{\mathrm{MSD}}^{\prime}(\lambda, \varphi)_{\mathrm{GPCP}}($ Fig. 2e $)$ & -0.55 \\
\hline 15 & $\operatorname{GPCP}_{\mathrm{REG}_{-} u^{\prime}}^{\prime}(\lambda, \varphi)_{\mathrm{M}, \mathrm{ON}}($ Fig. 11b) & $P_{\mathrm{MSD}}^{\prime}(\lambda, \varphi)_{\mathrm{GPCP}}($ Fig. 2e) & -0.43 \\
\hline
\end{tabular}

$(\mathrm{yy}, \mathrm{JJAS}, \mathrm{dd}), u_{\mathrm{REG} \_u}(\lambda, \varphi)$ and $Z_{\mathrm{REG} \_u}(\lambda, \varphi)$ (Figs. 5a,b), with $u_{\mathrm{MSD}}(\lambda, \varphi)$ and $Z_{\mathrm{MSD}}(\lambda, \varphi)$ (Table 2, rows 4 and 5), are higher compared to those between the regressed $u$ and $Z$ fields onto $u_{\text {CLLJ }}, u_{\text {REG_CLLJ }}(\lambda, \varphi)$ and $Z_{\text {REG_CLLJ }}(\lambda, \varphi)$ (Figs. $5 \mathrm{c}$,d) with $u_{\mathrm{MSD}}(\lambda, \varphi)$ and $Z_{\mathrm{MSD}}(\lambda, \varphi)$ (Table 2, rows 6 and 7).

As shown in Fig. 6, $u_{10 \mathrm{~N}, 90 \mathrm{w}}$ (yy, mm, dd) captures the temporal signals of the evolution of the climatological MSD. By dividing $u_{10 \mathrm{~N}, 90 \mathrm{w}}$ (yy, JJAS, dd) into terciles, the bottom tercile is formed by easterlies that mainly occur during July and August (Fig. 6b); the middle tercile is formed by weak easterlies and westerlies that are randomly distributed in time (Fig. 6c); but the top tercile is formed by westerlies during June and September (Fig. 6d). Consistently with the evolution of the climatological MSD, $u_{10 \mathrm{~N}, 90 \mathrm{w}}$ (yy, mm, dd) has a bimodal frequency distribution in its JJAS climatology, $u_{10 \mathrm{~N}, 90 \mathrm{~W}}$ ([yy], JJAS, dd) (Fig. 7a). One mode has negative values (an easterly regime) and the other positive values (a westerly regime); evidently, both modes are respectively caused by the climatological easterly (July-August) and westerly (June and September) winds in JJAS (Figs. 3a,b and 6 ).

Although the anomalous easterlies in the constructed index during JJAS, $u_{10 \mathrm{~N}, 90 \mathrm{w}}^{\prime}(\mathrm{yy}, \mathrm{JJAS}$, "easterlies"), occur randomly (as expected; Fig. 7b), their associated a) $u$ regressed onto $u_{90 \mathrm{~W}, 10 \mathrm{~N}}$

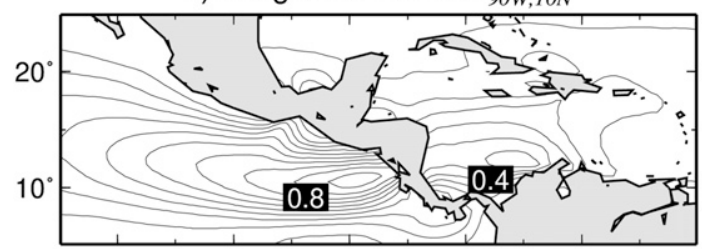

c) $u$ regressed onto $u_{C L L J}$

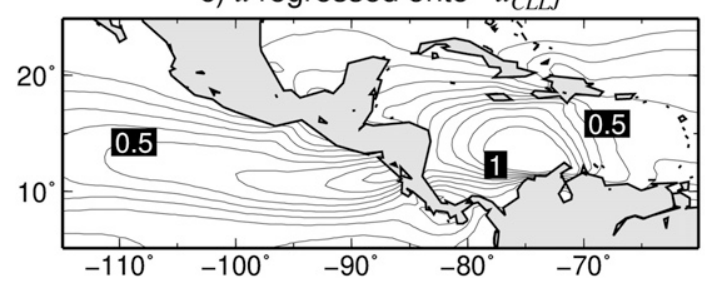

b) $Z$ regressed onto $u_{90 \mathrm{~W}, 10 \mathrm{~N}}$

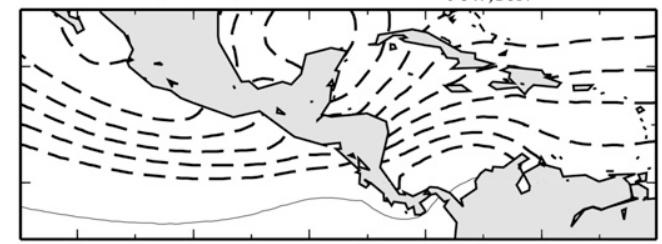

d) $Z$ regressed onto $u_{C L L J}$

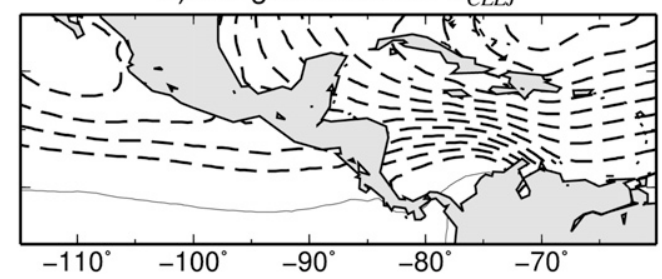

FIG. 5. Regression maps of (a),(c) zonal winds $\left(u ; \mathrm{m} \mathrm{s}^{-1}\right.$ per $\left.\mathrm{m} \mathrm{s}^{-1}\right)$ and (b),(d) geopotential height $(Z$; contour intervals of $3 \mathrm{~m}$ per $\mathrm{m} \mathrm{s}^{-1}$; solid contours for positive and dashed for negative values) onto zonal winds from two time series: from a grid point at $10^{\circ} \mathrm{N}, 90^{\circ} \mathrm{W}, u_{10 \mathrm{~N}, 90 \mathrm{~W}}$, and from the area average over $128^{\circ}-158^{\circ} \mathrm{N}, 70^{\circ}-75^{\circ} \mathrm{W}, u_{\mathrm{CLLJ}}$. All data are at daily resolution, at the 925 -hPa vertical pressure level during JJAS from ERA Interim. Only regressions significant at the $95 \%$ confidence level are shown. 

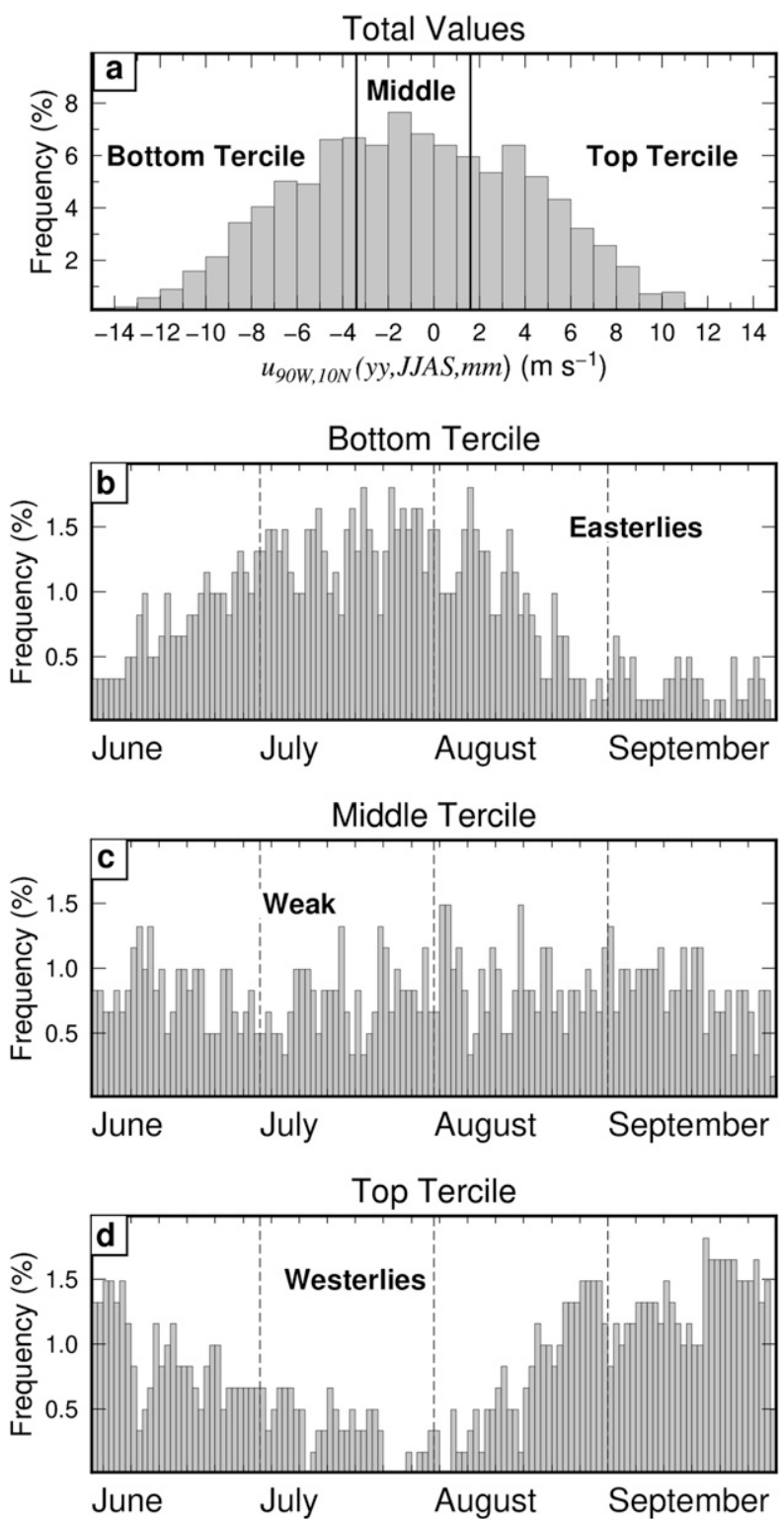

FIG. 6. Frequency distributions of daily zonal winds at $10^{\circ} \mathrm{N}$, $90^{\circ} \mathrm{W}, u_{10 \mathrm{~N}, 90 \mathrm{~W}}(\mathrm{yy}, \mathrm{mm})$, ordered by (a) its values, and by the dates of its values in their (b) bottom, (c) middle, and (d) upper speed terciles in JJAS at the 925-hPa vertical pressure level from ERA Interim.

$P$ composites, $P^{\prime}(\lambda, \varphi,[\mathrm{yy}],[\mathrm{JJAS}],[$ [easterlies"] $)$, contain the features of $P_{\mathrm{MSD}}(\lambda, \varphi)$ (Fig. 8a; Table 2, row 7). Also, their associated $u, v$, and $Z$ composites, $u^{\prime}(\lambda, \varphi$, [yy], [JJAS], [“easterlies”] $), v^{\prime}(\lambda, \varphi$, [yy], [JJAS], ["easterlies"]), and $Z^{\prime}(\lambda, \varphi$, [yy], [JJAS], ["easterlies"]), contain the features of $u_{\mathrm{MSD}}(\lambda, \varphi), v_{\mathrm{MSD}}$ $(\lambda, \varphi)$, and $Z_{\mathrm{MSD}}(\lambda, \varphi)$ (Fig. 8b; Table 2, row 8). Notably, these composites of daily anomalies resemble the patterns of the monthly climatological MSD (Figs. 2 and 3).
So far our results (e.g., Figs. 4 and 8 ) suggest a mechanistic relation between two anomalous fields: enhanced easterlies impinging over eastern Central America related, and MSD-like patterns in rainfall (the opposite relation is also valid). To further explore such relation, we regressed daily rainfall anomalies of $P^{\prime}(\lambda, \varphi, \mathrm{yy}, \mathrm{mm}, \mathrm{dd})$ onto $u_{10 \mathrm{~N}, 90 \mathrm{w}}^{\prime}(\mathrm{yy}, \mathrm{mm}$, dd) during JJAS, March, October and November (M,ON; rainy-season months), and December to April (DJFMA; dry season months). The results from these analyses show that, in the regressed daily precipitation anomalies, $P_{\mathrm{REG}_{2} u}^{\prime}(\lambda, \varphi)_{\mathrm{mm}}, P_{\mathrm{MSD}}(\lambda, \varphi)$ signals do not clearly emerge during the dry months: they are absent in $P_{\text {REG } \_u}^{\prime}(\lambda, \varphi)_{\text {DJFMA }}$ (Fig. 9a; Table 2, row 12). However, $P_{\mathrm{MSD}}(\lambda, \varphi)$ signals do emerge during the rainy months: they emerge during JJAS, $P_{\mathrm{REG}_{-} u}^{\prime}(\lambda, \varphi)_{\text {JJAS }}$ (Fig. 9b; Table 2, row 10) and also during M,ON, $P_{\text {REG_u }}^{\prime}(\lambda, \varphi)_{\mathrm{M}, \mathrm{ON}}$ (Fig. 9c; Table 2, row 11). These findings are further strengthened by replication with other datasets (e.g., CFSR and PERSIANN; Figs. 9d-f).

Since the regressed $P_{\mathrm{REG} \_u}^{\prime}(\lambda, \varphi)_{\mathrm{JJAS}}$ and $P_{\mathrm{REG} \_u}^{\prime}(\lambda, \varphi)_{\mathrm{M}, \mathrm{ON}}$ (Figs. 9b,c) adequately capture daily anomalous variability with $P_{\mathrm{MSD}}(\lambda, \varphi)$ features, they were used to roughly estimate the explained variance by variability with MSD-like features in daily time scales. The variance of such variability is related to that of the total daily anomalies by

$$
\begin{aligned}
& \operatorname{var}_{\text {space-time }}\left[P^{\prime}(\lambda, \varphi, \mathrm{yr}, \mathrm{mm}, \mathrm{dd})\right] \\
& \quad=\operatorname{var}_{\text {space-time }}\left[P_{\mathrm{REG} \_u}^{\prime}(\lambda, \varphi, \mathrm{yy}, \mathrm{mm}, \mathrm{dd})\right]+R_{\mathrm{mm}},
\end{aligned}
$$

where $P_{\mathrm{REG} u}^{\prime}(\lambda, \varphi, \mathrm{yy}, \mathrm{mm}, \mathrm{dd})$ is the product of $P_{\mathrm{REG}_{-} u}^{\prime}(\lambda, \varphi)$ and $u_{90 \mathrm{~W}, 10 \mathrm{~N}}^{\prime}(\mathrm{yy}, \mathrm{mm}, \mathrm{dd})$ and $R_{\mathrm{mm}}$ is the variance attributable to anomalous, daily variability without MSD-like features (residual variance).

The results of Eq. (9) applied to the JJAS and M,ON daily data (Table 1, rows 9-14) show that the attributable variance to anomalous daily variability with $P_{\mathrm{MSD}}(\lambda, \varphi)$ features (Table 1, rows 9 and 12) is almost negligible with respect to their seasonal totals: it is $1.9 \%$ in JJAS (Table 1, row 11), and it is $1.3 \%$ in M,ON (Table 1, row 14 ). In both seasons, roughly $90 \%$ of the daily anomalous variance is residual (Table 1 , compare rows 10-13). Although the amount of explained variance by variability with $P_{\mathrm{MSD}}(\lambda, \varphi)$ features is small, their mere existence is notable: no other daily-resolution signals of the anomalous rainfall variability are known to be present in all months of the rainy season.

\section{d. Anomalous interannual wind-MSD patterns}

To investigate the repeatability of the MSD pattern in interannual time scales, we first investigated the spatial pattern of rainfall anomalies during ENSO episodes. We 

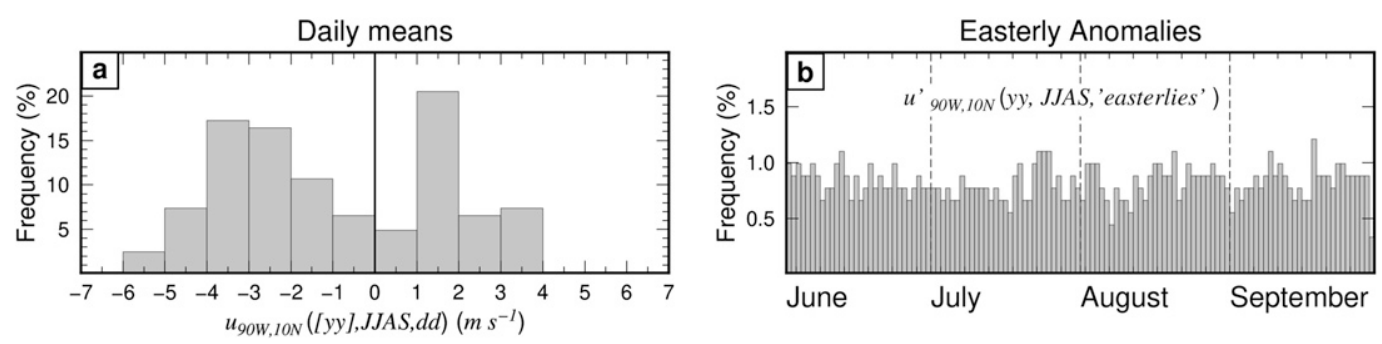

FIG. 7. As in Fig. 6, but for (a) daily means ordered by its speed, and for (b) negative anomalies (easterlies) ordered by its dates.

identified "El Niño" ("La Niña") episodes as those having seasonal-mean $\mathrm{SST}_{3.4}$ (yy, [mm]) above (below) $0.5^{\circ} \mathrm{C}\left(-0.5^{\circ} \mathrm{C}\right)$ in the $1979-2017$ period. We found the largest MSD-like signals in ENSO rainfall composites during JJAS. During this season, the composited "El Niño" rainfall anomalies, $\operatorname{GPCP}^{\prime}(\lambda, \varphi$, ["El Niño"], [JJAS]), have clear spatial features that resemble those in $P_{\mathrm{MSD}}(\lambda, \varphi)$ (Fig. 10a; Table 2, row 13): they have the characteristic dry anomalies located over the Caribbean, Central America, and southern Mexico, and they have the characteristic wet anomalies over the EPAC, those associated to a westward displacement of the ITCZ by anomalous easterlies. Although this composite has weak MSD-like signals over the eastern coasts of Costa Rica and Nicaragua, those signals are generally weak in GPCP (Figs. 2e,f). In "La Niña" composites, $\operatorname{GPCP}^{\prime}(\lambda, \varphi$, ["La Niña"], [JJAS]) (Fig. 10b), few statistically significant signals were found, but those signals and its overall pattern consistently show the wet face of $P_{\mathrm{MSD}}(\lambda, \varphi)$ that is associated with anomalous westerlies.

To further investigate the relation MSD-like shaped rainfall anomalies and between SST anomalies in interannual scales, we diagnosed seasonal-mean anomalies [Eq. (3)] using two analyses: 1) we regressed rainfall, $\operatorname{GPCP}^{\prime}(\lambda, \varphi, y y)_{\mathrm{mm}}$, onto our implemented wind index, $u_{10 \mathrm{~N}, 90 \mathrm{~W}}^{\prime}(\mathrm{yy})_{\mathrm{mm}}$, and 2) we correlated that index with SST, $\operatorname{SST}_{3.4}^{\prime}(\mathrm{yy})_{\mathrm{mm}}$. The first analysis shows $P_{\mathrm{MSD}}(\lambda, \varphi)$ signals in the regressed rainfall of both seasons, $\operatorname{GPCP}_{\mathrm{REG} \_u}^{\prime}(\lambda, \varphi)_{\mathrm{JJAS}}$ and $\operatorname{GPCP}_{\mathrm{REG} \_u}^{\prime}(\lambda, \varphi)_{\mathrm{M}, \mathrm{ON}}$, but particularly in JJAS (Fig. 11; Table 2, rows 14 and 15). The second analysis shows warm (cold) SST anomalies that are well correlated with easterly (westerly) wind anomalies in both seasons, but particularly in JJAS (Fig. 12). These results provide support to two possible implications about the causes behind the emergence of MSD-like rainfall patterns in interannual time scales. First, regardless of the ENSO phase, the intensity in anomalous lower-tropospheric winds tends to modulate the intensity and sign of the recurring MSD-like patterns in rainfall. Second, MSDlike patterns emerge following lower-tropospheric wind perturbations, regardless of whether they move into the IAS from its eastern side or from its western side.

Since the regressed rainfall-anomaly maps, $\mathrm{GPCP}_{\mathrm{REG} \_u}^{\prime}$ $(\lambda, \varphi, \mathrm{yy})_{\mathrm{JJAS}}$ and $\mathrm{GPCP}_{\mathrm{REG} \_u}^{\prime}(\lambda, \varphi, \mathrm{yy})_{\mathrm{M}, \mathrm{ON}}($ Fig. 11) (Figs. 9b,c), adequately capture interannual variability with $P_{\mathrm{MSD}}(\lambda, \varphi)$ signals, they were used to roughly estimate the explained variance by variability with MSD-like features in interannual time scales. The variance of such variability is related to that of the total interannual anomalies by

$$
\begin{aligned}
& \operatorname{var}_{\text {space-time }}\left[\operatorname{GPCP}^{\prime}(\lambda, \varphi, \mathrm{yr})_{\mathrm{mm}}\right] \\
& \quad=\operatorname{var}_{\text {space-time }}\left[\operatorname{GPCP}_{\mathrm{REG} \_u}^{\prime}(\lambda, \varphi, \mathrm{yy})_{\mathrm{mm}}\right]+R_{\mathrm{yy} \_\mathrm{mm}},
\end{aligned}
$$

where $\operatorname{GPCP}_{\mathrm{REG} \_u}^{\prime}(\lambda, \varphi, \mathrm{yy})_{\mathrm{mm}}$ is the product of $\operatorname{GPCP}_{\mathrm{REG} \_u}^{\prime}(\lambda, \varphi)$ and $u_{10 \mathrm{~N}, 90 \mathrm{~W}}(\mathrm{yy},[\mathrm{mm}])$ and $R_{\mathrm{yy} \_\mathrm{mm}}$ is the variance attributable to anomalous interannual variability without MSD-like features (residual variance) for a given season. Table 1 (rows 15-18) shows that the variance roughly
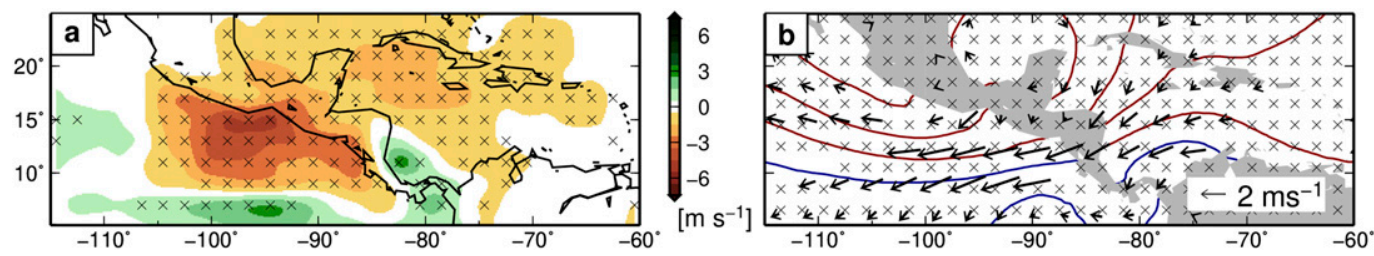

FIG. 8. Daily anomalies of (a) TRMM 3B42 $\left(P^{\prime}\right)$, and (b) 925-hPa horizontal wind (arrows) and geopotential height ( $Z^{\prime}$; contours every $2 \mathrm{~m}$ ) from ERA-Interim composited in days of easterly anomalies during JJAS at $10^{\circ} \mathrm{N}$, $90^{\circ} \mathrm{W}$. Only statistically significant winds at the $95 \%$ level are shown; crosses indicate statistical significance in either $P^{\prime}$ or $Z^{\prime}$. Positive contours of $Z^{\prime}$ are red and negative contours are blue. 
DJFMA
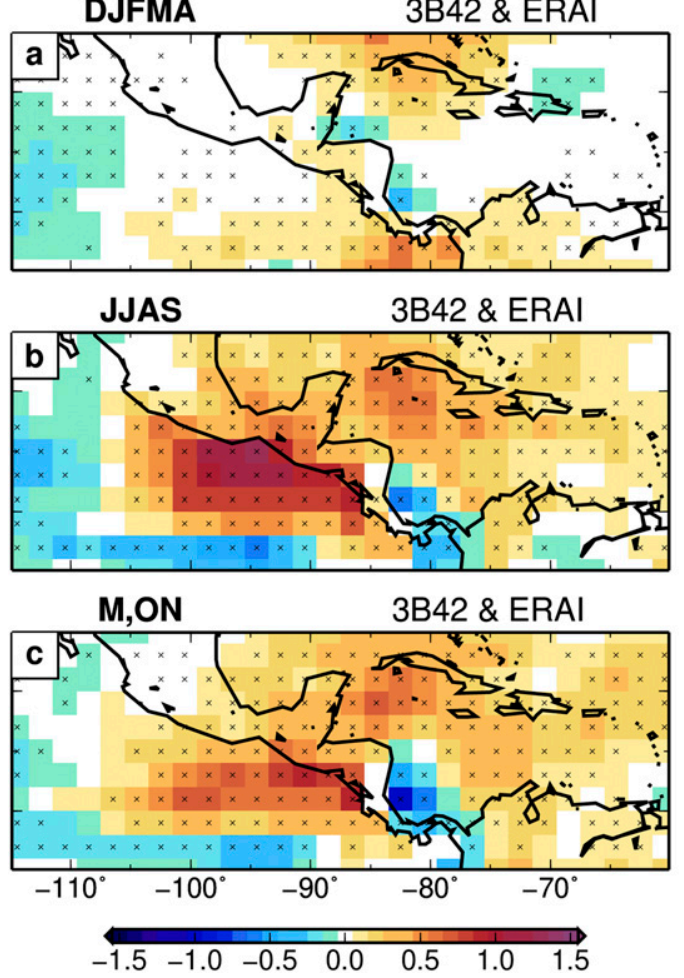

DJFMA
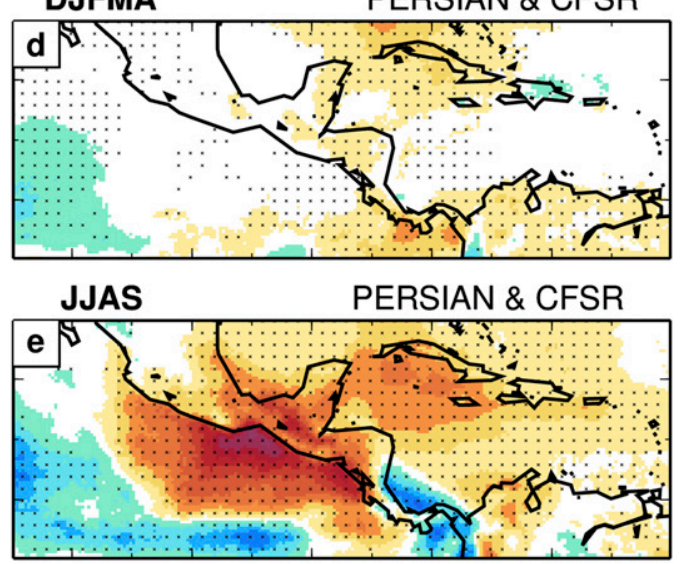

M,ON

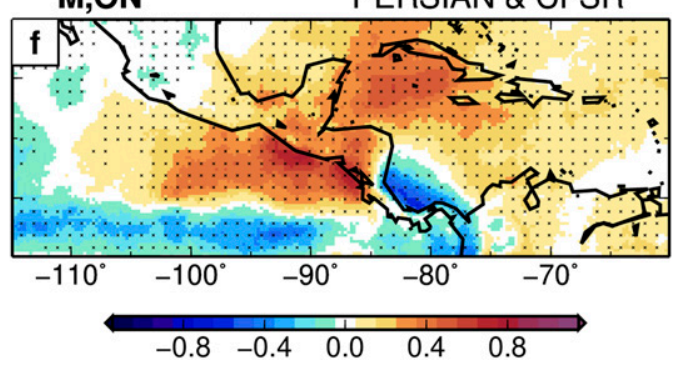

FIG. 9. Regression maps of daily precipitation anomalies onto the time series anomalous 925-hPa zonal winds at $10^{\circ} \mathrm{N}, 90^{\circ} \mathrm{W}\left(\mathrm{mm} \mathrm{day}^{-1}\right.$ per $\mathrm{m} \mathrm{s}^{-1}$ ) for (a) December to May (DJFMAM), (b) June to September (JJAS), and (c) May, October, and November (M,ON) using TRMM $\left(2^{\circ} \times 2^{\circ}\right)$ and ERA-Interim, and (d)-(f) their replicated versions using PERSIANN $\left(0.25^{\circ} \times 0.25^{\circ}\right)$ and CFSR. Crosses indicate statistical significance at the $95 \%$ confidence level.

attributable to variability with $P_{\mathrm{MSD}}(\lambda, \varphi)$ features is relatively high, during $\mathrm{M}, \mathrm{ON}$ is $10 \%$, and during JJAS is $20 \%$.

\section{Summary and conclusions}

We applied statistical analyzes to rainfall and reanalysis data at different temporal resolutions in order to investigate the idea that the pattern of the climatological MSD manifest an underlying master pattern for rainfall anomalies across different time scales. In particular, we evaluated 1) the repeatability of MSD-like patterns and 2) their attributable contribution to the total variance. Our results indicate that the MSD pattern emerges as anomalous variability on daily, monthly, and interannual time scales in all rainy seasons.
Although MSD-like patterns more robustly emerge in JJAS, they are present in all rainy seasons. With respect to the explained variance by MSD-like patterns, our results indicate that it is negligible in diurnal time scales (less than $2 \%$ ), but it is substantial in monthly and interannual time scales (up to $20 \%$ ).

Aside from the repeatable nature of the MSD pattern, our results showed that, in either daily or interannual time resolutions, MSD-like rainfall patterns are accompanied by a domain-wide, anomalous northward meridional pressure gradient with underlying anomalous easterlies over the Caribbean and intense gap winds over the EPAC. Clearly, the more intense the anomalous gradient and wind speeds are, the more intensely the MSD-shaped patterns in
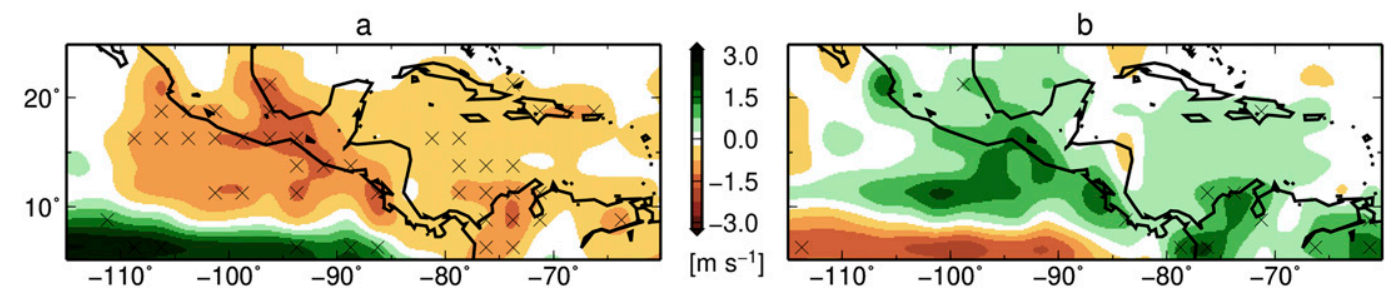

FIG. 10. Composited JJAS rainfall anomalies during (a) "El Niño" and (b) "La Niña" events from GPCP. Crosses indicate statistical significance at the $95 \%$ confidence level. 
a) JJAS

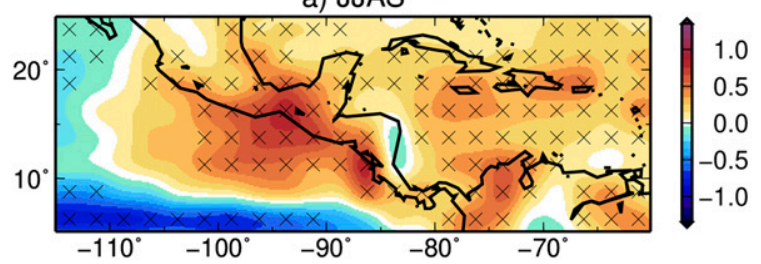

b) M,ON

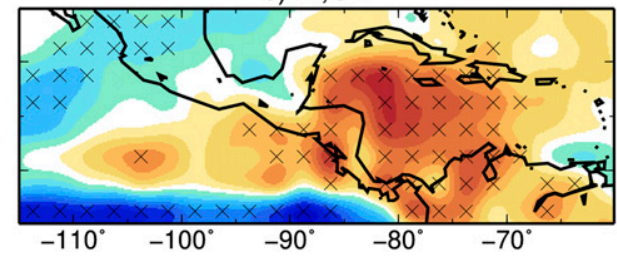

FIG. 11. As in Fig. 9, but for GPCP anomalies in (a) JJAS and (b) M,ON over the 1979-2017 period.

rainfall emerge. To explore if different intensities of the MSD pattern in daily time scales can be attributed to moisture variations in the anomalous easterlies, we regressed rainfall onto anomalous zonal moisture fluxes but found the same results: almost negligible explained variance $(<2 \%)$. Such results suggest that domain-wide wind speed variations, rather than moisture variations, cause MSD-like rainfall patterns.

The findings presented in this study might serve as evidence to the formal hypothesis that a mechanistic, geographically determined pattern is behind the multiscale MSD-like signals highlighted in this study. A proof for this hypothesis, ideally, would include a formula to determine such a pattern, would be supported by numerical experiments, and would be examined under the formal-hypothesis framework that this study lacked. If such a master pattern indeed exists, it might have peers in other regions; perhaps the anomalous rainfall signals that emerge over the East Asian Maritime Continent during the easterly regime that precedes the arrival of MJO events (e.g., Zhang and Ling 2017) manifest a master pattern in that region.

Regardless of the validity of the proposed hypothesis, our findings do show that the MSD pattern is not uniquely related to the summer intraseasonal variability of the IAS. Also, our diagnosis that wind and rainfall patterns with MSD-like features are repetitive in different time scales might explain, albeit partially, why several previous studies have found similar signals in many different time scales: on 18-day scales (Jiang and Waliser 2009), subseasonal scales (Vigaud and Robertson 2017), seasonal and interannual scales (Wang 2007; Cook and Vizy 2010), and even decadal scales (Méndez and Magaña 2010).

Our findings might also help to explain the disputed role of the MJO with regard to the climatological MSD. While previous studies have attributed the onset of the climatological MSD to the passing of the MJO over the IAS (Maloney and Kiehl 2002), others have argued that this idea might not hold under further examination since the MSD is phase-locked but the MJO is not (Magaña and Caetano 2005). According to our findings, MSD-like rainfall patterns might be caused by the MJO or by any other perturbation that enhances easterlies over the whole domain. Such perturbation might come from the east or from the west (such as NASH intrusions; Kelly and Mapes 2011, 2013), and might be phase locked or might not be. Therefore, our results suggest that the MJO
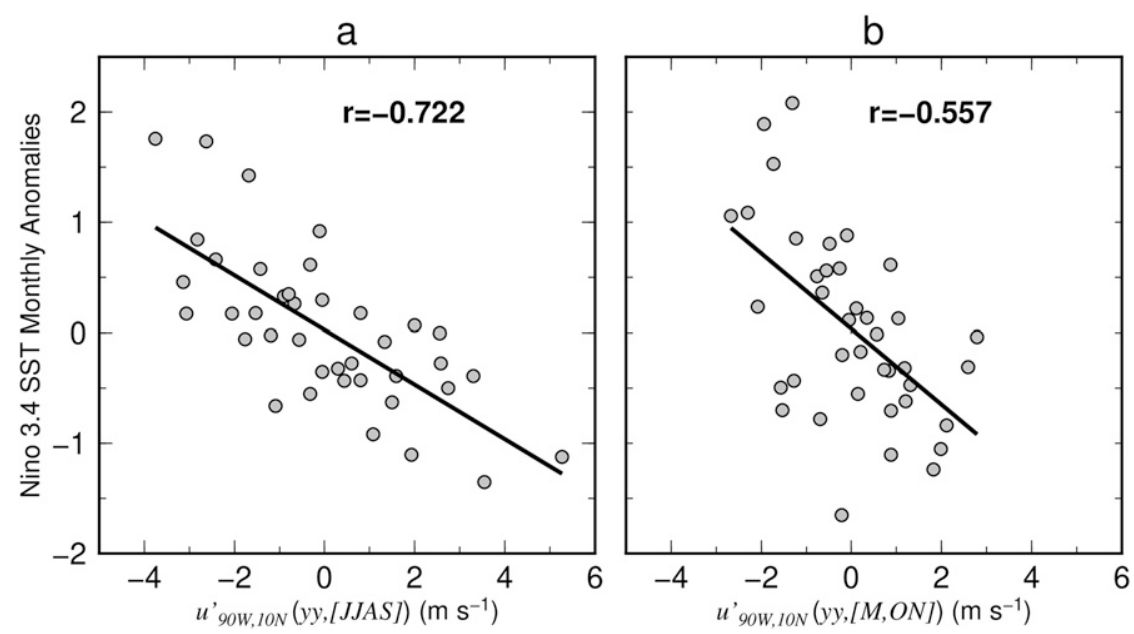

FIG. 12. Scatter diagrams of (a) JJAS and (b) M,ON seasonal anomalies in 925-hPa zonal winds at $10^{\circ} \mathrm{N}, 90^{\circ} \mathrm{W}$, from ERA Interim and in Niño-3.4 SST during 1979-2017. 
may be one of the causes of the climatological MSD, but it may also be one of the causes of anomalous MSD-like patterns in any other month of the rainy season.

This study also showed that, at least during boreal summer, "El Niño" rainfall anomalies resemble MSDlike patterns. It may come as no surprise that both the MSD and "El Niño" are known for their similar impacts over Central America and southern Mexico: reduced water availability, high surface temperatures, forest fires, and so on (e.g., Magaña 2004). Such similarities between MSD-like rainfall patterns and the impacts of long-term variability on the regional water availability might hold interesting historical implications: Perhaps anomalous MSD-like rainfall patterns with underlying easterlies were behind the devastating droughts over south Mexico and Central America that decimated the population hundreds of years ago (Acuña-Soto et al. 2002; Therrell et al. 2004) or behind those that caused the fall of the Mayan civilization (Hodell et al. 1995).

According to our results, the intensity of anomalous easterlies over the IAS could be used to interpret the intensity of MSD-like rainfall anomalies. Since this relation explains a significant amount of variance in interannual time scales, it could be used not only to better understand the climatic causes behind past droughts and pluvials, but also to predict future ones and to diagnose rainfall trends. In such work, an important concern would be to identify the processes that enhance or weaken domain-wide easterlies; as shown in this study, an index based on the Papagayo gap winds might help to address the problem.

Acknowledgments. The author particularly thanks Brian Mapes and Elinor Martin for their many insightful comments and suggestions. Also, the author thanks an anonymous reviewer. The origins of this study were motivated by talks with Víctor Magaña. This study is part of the results of a DGAPA-PAPIIT project (IA106018). This study could not have been possible without GNU software and freely available data from ECMWF, CFSR, PERSIANN, and NASA.

\section{REFERENCES}

Acuña-Soto, R., L. D. W. Stahle, M. K. Cleaveland, and M. D. Therrell, 2002: Megadrought and megadeath in 16th century Mexico. Emerg. Infect. Dis., 8, 360-362, https://doi.org/ 10.3201/eid0804.010175.

Adler, R. F., and Coauthors, 2003: The version 2 Global Precipitation Climatology Project (GPCP) monthly precipitation analysis (1979-present). J. Hydrometeor., 4, 1147-1167, https://doi.org/ 10.1175/1525-7541(2003)004<1147:TVGPCP $>2.0$.CO;2.

Amador, J., E. J. Alfaro, O. G. Lizano, and V. O. Magaña, 2006: Atmospheric forcing of the eastern tropical Pacific: A review. Prog. Oceanogr., 69, 101-142, https://doi.org/10.1016/ j.pocean.2006.03.007.
Ashouri, H., K. Hsu, S. Sorooshian, D. K. Braithwaite, K. R. Knapp, L. D. Cecil, B. R. Nelson, and O. P. Prat, 2015: PERSIANN-CDR: Daily Precipitation Climate Data Record from Multisatellite Observations for Hydrological and Climate Studies. Bull. Amer. Meteor. Soc., 96, 69-83, https://doi.org/ 10.1175/BAMS-D-13-00068.1.

Biasutti, M., S. E. Yuter, C. D. Burleyson, and A. H. Sobel, 2012: Very high resolution rainfall patterns measured by TRMM precipitation radar: Seasonal and diurnal cycles. Climate Dyn., 39, 239-258, https://doi.org/10.1007/s00382-011-1146-6.

Cook, K., and E. Vizy, 2010: Hydrodynamics of the Caribbean lowlevel jet and its relationship to precipitation. J. Climate, 23, 1477-1494, https://doi.org/10.1175/2009JCLI3210.1.

Dee, D. P., and Coauthors, 2011: The ERA-Interim reanalysis: Configuration and performance of the data assimilation system. Quart. J. Roy. Meteor. Soc., 137, 553-597, https://doi.org/10.1002/qj.828.

Enfield, D.B. and E.J. Alfaro, 1999: The dependence of Caribbean rainfall on the interaction of the tropical Atlantic and Pacific Oceans. J. Climate, 12, 2093-2103, https://doi.org/10.1175/ 1520-0442(1999)012<2093:TDOCRO>2.0.CO;2.

Herrera, E., V. Magaña, and E. Caetano, 2015: Air-sea interactions and dynamical processes associated with the midsummer drought. Int. J. Climatol., 35, 1569-1578, https://doi.org/10.1002/joc.4077.

Hodell, D. A., J. H. Curtis, and M. Brenner, 1995: Possible role of climate in the collapse of Classic Maya civilization. Nature, 375, 391-394, https://doi.org/10.1038/375391a0.

Huang, B. Y., and Coauthors, 2017: Extended Reconstructed Sea Surface Temperature, version 5 (ERSSTv5): Upgrades, validations, and intercomparisons. J. Climate, 30, 8179-8205, https://doi.org/10.1175/JCLI-D-16-0836.1.

Huffman, G. J., and Coauthors, 2007: The TRMM Multisatellite Precipitation Analysis (TMPA): Quasi-global, multiyear, combined-sensor precipitation estimates at fine scales. J. Hydrometeor., 8, 38-55, https://doi.org/10.1175/JHM560.1.

Jiang, X., and D. Waliser, 2009: Two dominant subseasonal variability modes of the eastern Pacific ITCZ. Geophys. Res. Lett., 36, L04704, https://doi.org/10.1029/2008GL036820.

Johnson, R. H., P. E. Ciesielski, B. D. McNoldy, P. J. Rogers, and R. K. Taft, 2007: Multiscale variability of the flow during the North American Monsoon Experiment. J. Climate, 20, 16281648, https://doi.org/10.1175/JCLI4087.1.

Karnauskas, K. B., R. Seager, A. Giannini, and A. J. Busalacchi, 2013: A simple mechanism for the climatological midsummer drought along the Pacific coast of Central America. Atmósfera, 26, 261-281, https://doi.org/10.1016/S0187-6236(13)71075-0.

Kelly, P., and B. E. Mapes, 2011: Zonal mean wind, the Indian monsoon, and July drying in the western Atlantic subtropics. J. Geophys. Res., 116, D00Q07, https://doi.org/10.1029/2010JD015405.

$\longrightarrow$, and 2013: Asian monsoon forcing of subtropical easterlies in the Community Atmosphere Model: Summer climate implications for the western Atlantic. J. Climate, 26, 27412755, https://doi.org/10.1175/JCLI-D-12-00339.1.

Kikuchi, K., and B. Wang, 2008: Diurnal precipitation regimes in the global tropics. J. Climate, 21, 2680-2696, https://doi.org/ 10.1175/2007JCLI2051.1.

Kirshbaum, D. J., 2011: Cloud-resolving simulations of deep convection over a heated mountain. J. Atmos. Sci., 68, 361-378, https://doi.org/10.1175/2010JAS3642.1.

Magaña, V., Ed., 2004: Los impactos del Niño en México. Centro de Ciencias de la Atmósfera, Universidad Nacional Autónoma de México, Secretaría de Gobernación, 229 pp., http:// centro.paot.org.mx/index.php/porinstituciones/otros-organismos/ 73-varios/745-los-impactos-de-el-nino-en-mexico. 
, and E. Caetano, 2005: Temporal evolution of summer convective activity over the Americas warm pools. Geophys. Res. Lett., 32, L02803, https://doi.org/10.1029/2004GL021033.

_ J. A. Amador, and S. Medina, 1999: The midsummer drought over Mexico and Central America. J. Climate, 12, 1577-1588, https:// doi.org/10.1175/1520-0442(1999)012<1577:TMDOMA>2.0.CO;2.

Maloney, E. D., and J. T. Kiehl, 2002: MJO-related SST variations over the tropical eastern Pacific during Northern Hemisphere summer. J. Climate, 15, 675-689, https://doi.org/10.1175/15200442(2002)015<0675:MRSVOT>2.0.CO;2.

Mapes, B. E., T. T. Warner, and M. Xu, 2003: Diurnal patterns of rainfall in northwestern South America. Part III: Diurnal gravity waves and nocturnal convection offshore. Mon. Wea. Rev., 131, 830-844, https:// doi.org/10.1175/1520-0493(2003)131<0830:DPORIN > 2.0.CO;2.

_- P. Liu, and N. Buenning, 2005: Indian monsoon onset and the Americas midsummer drought: Out-of-equilibrium responses to smooth seasonal forcing. J. Climate, 18, 1109-1115, https:// doi.org/10.1175/JCLI-3310.1.

Martin, E., and C. Schumacher, 2011a: Modulation of Caribbean precipitation by the Madden-Julian oscillation. J. Climate, 24, 813-824, https://doi.org/10.1175/2010JCLI3773.1.

— lationship with precipitation in the IPCC AR4 models. J. Climate, 24, 5935-5950, https://doi.org/10.1175/JCLI-D-11-00134.1.

Méndez, M., and V. Magaña, 2010: Regional aspects of prolonged meteorological droughts over Mexico and Central America. J. Climate, 23, 1175-1188, https://doi.org/10.1175/ 2009JCLI3080.1.

Mestas-Nuñez, A., D. Enfield, and C. Zhang, 2007: Water vapor fluxes over the Intra-Americas Sea: Seasonal and interannual variability and associations with rainfall. J. Climate, 20, 19101922, https://doi.org/10.1175/JCLI4096.1.

Navarra, A., and V. Simoncini, 2010: A Guide to Empirical Orthogonal Functions for Climate Data Analysis. Springer-Verlag, 151 pp.

Nesbitt, S. W., and E. J. Zipser, 2003: The diurnal cycle of rainfall and convective intensity according to three years of TRMM measurements. J. Climate, 16, 1456-1475, https://doi.org/ 10.1175/1520-0442-16.10.1456

Saha, S., and Coauthors, 2010: The NCEP Climate Forecast System Reanalysis. Bull. Amer. Meteor. Soc., 91, 1015-1057, https:// doi.org/10.1175/2010BAMS3001.1.

Serra, Y., G. Kiladis, and K. Hodges, 2010: Tracking and mean structure of easterly waves over the Intra-Americas Sea. J. Climate, 23, 4823-4840, https://doi.org/10.1175/2010JCLI3223.1.

Small, R. J. O., S. P. de Szoeke, and S.-P. Xie, 2007: The Central American midsummer drought: Regional aspects and large-scale forcing. J. Climate, 20, 4853-4873, https://doi.org/ 10.1175/JCLI4261.1.

Sobel, A. H., C. D. Burleyson, and S. E. Yuter, 2011: Rain on small tropical islands. J. Geophys. Res., 116, D08102, https://doi.org/ 10.1029/2010JD014695.

Sorooshian, S., X. Gao, K. Hsu, R. A. Maddox, Y. Hong, H. V. Gupta, and B. Imam, 2002: Diurnal variability of tropical rainfall retrieved from combined GOES and TRMM satellite information. J. Climate, 15, 983-1001, https://doi.org/10.1175/ 1520-0442(2002)015<0983:DVOTRR > 2.0.CO;2.

Therrell, M. D., D. W. Stahle, and R. Acuña-Soto, 2004: Aztec drought and the "curse of One Rabbit." Bull. Amer. Meteor. Soc., 85, 1263-1272, https://doi.org/10.1175/BAMS-85-9-1263.

Vigaud, N., and A. W. Robertson, 2017: Convection regimes and tropical-midlatitude interactions over the Intra-American Seas from May to November. Int. J. Climatol., 37, 987-1000, https://doi.org/10.1002/joc.5051.

Wallace, J. M., C. Smith, and C. S. Bretherton, 1992: Singular value decomposition of wintertime sea surface temperature and 500-mb height anomalies. J. Climate, 5, 561-576, https://doi.org/ 10.1175/1520-0442(1992)005<0561:SVDOWS >2.0.CO;2.

Wang, C., 2007: Variability of the Caribbean low-level jet and its relations to climate. Climate Dyn., 29, 411-422, https://doi.org/ 10.1007/s00382-007-0243-z.

__ and S.-K. Lee, 2007: Atlantic warm pool, Caribbean low-level jet, and their potential impact on Atlantic hurricanes. Geophys. Res. Lett., 34, L02703, https://doi.org/10.1029/2006GL028579.

Wang, S., and A. H. Sobel, 2017: Factors controlling rain on small tropical islands: Diurnal cycle, large-scale wind speed, and topography. J. Atmos. Sci. 74, 3515-3532, https://doi.org/10.1175/JASD-16-0344.1.

Whitaker, J., and E. Maloney, 2018: Influence of the MaddenJulian oscillation and Caribbean low-level jet on east Pacific easterly wave dynamics. J. Atmos. Sci., 75, 1121-1141, https:// doi.org/10.1175/JAS-D-17-0250.1.

Xie, S.-P., H. Xu, W. S. Kessler, and M. Nonaka, 2005: Air-sea interaction over the eastern Pacific warm pool: Gap winds, thermocline dome, and atmospheric convection. J. Climate, 18, 5-20, https://doi.org/10.1175/JCLI-3249.1.

Yang, G.-Y., and J. Slingo, 2001: The diurnal cycle in the tropics. Mon. Wea. Rev., 129, 784-801, https://doi.org/10.1175/15200493(2001)129<0784:TDCITT>2.0.CO;2.

Zhang, C., and J. Ling, 2017: Barrier effect of the Indo-Pacific Maritime Continent on the MJO: Perspectives from tracking MJO precipitation. J. Climate, 30, 3439-3459, https://doi.org/ 10.1175/JCLI-D-16-0614.1. 